\title{
Late Quaternary geology of a potential wind-farm area in the Kattegat, southern Scandinavia
}

\author{
Jørgen O. Leth and Bernhard Novak
}

Following the proposal of the offshore Anholt wind-farm project with an energy capacity of 400 megawatt in the Kattegat, southern Scandinavia, an evaluation of the geotechnical properties of the subsurface of the area is required. As a first step to map the seabed geology the Geological Survey of Denmark and Greenland (GEUS) conducted a geophysical survey (Leth et al. 2009) which, together with cone penetration tests and data from boreholes, lead to a greater understanding of the geological architecture and development of the $144 \mathrm{~km}^{2}$ survey area (Figs 1,2).

\section{Methods}

We used a multibeam echo-sounder for detailed mapping of the bathymetry, and shallow seismic equipment and coring to map the shallow seabed geology including the distribution and thickness of the main geological units. A combination of two seismic devices (chirp and sparker systems) was chosen to ensure good penetration and high resolution. The sparker system provides data from the sea floor down to about $45 \mathrm{~m}$

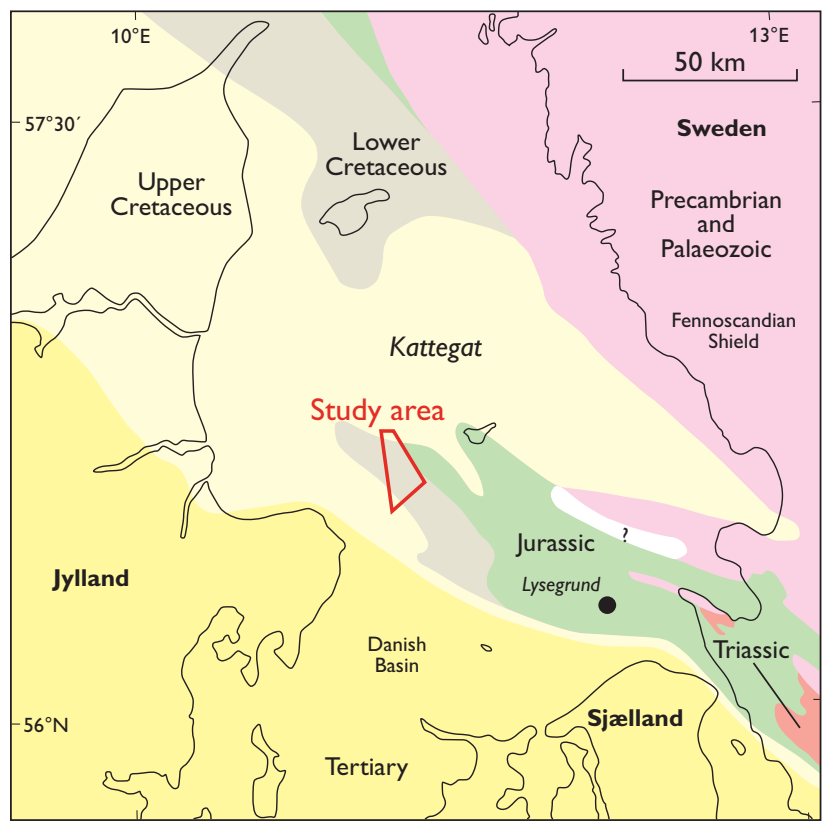

Fig. 1. Pre-Quaternary geology of the Kattegat. Redrawn and simplified from Lykke-Andersen et al. (1993). into the seabed with a vertical seismic resolution in the order of $50 \mathrm{~cm}$, while the chirp system provides high-resolution seismic data from the upper 5-10 m of the seabed with a vertical seismic resolution at decimetre scale. A side-scan sonar was used for mapping of surface sediments. At seven sites, boreholes were made to a depth of $40 \mathrm{~m}$ and selected intervals sampled. Cone penetration tests were carried out at the same sites (Fig. 2) and surface sediment samples collected for biological studies.

\section{Geological setting and seabed}

The Kattegat region is located in the transition zone between the Fennoscandian Shield and the Danish Basin (Fig. 1), and studies of the pre-Quaternary surface morphology show that the NW-SE-trending anticlinorium follows the trend of

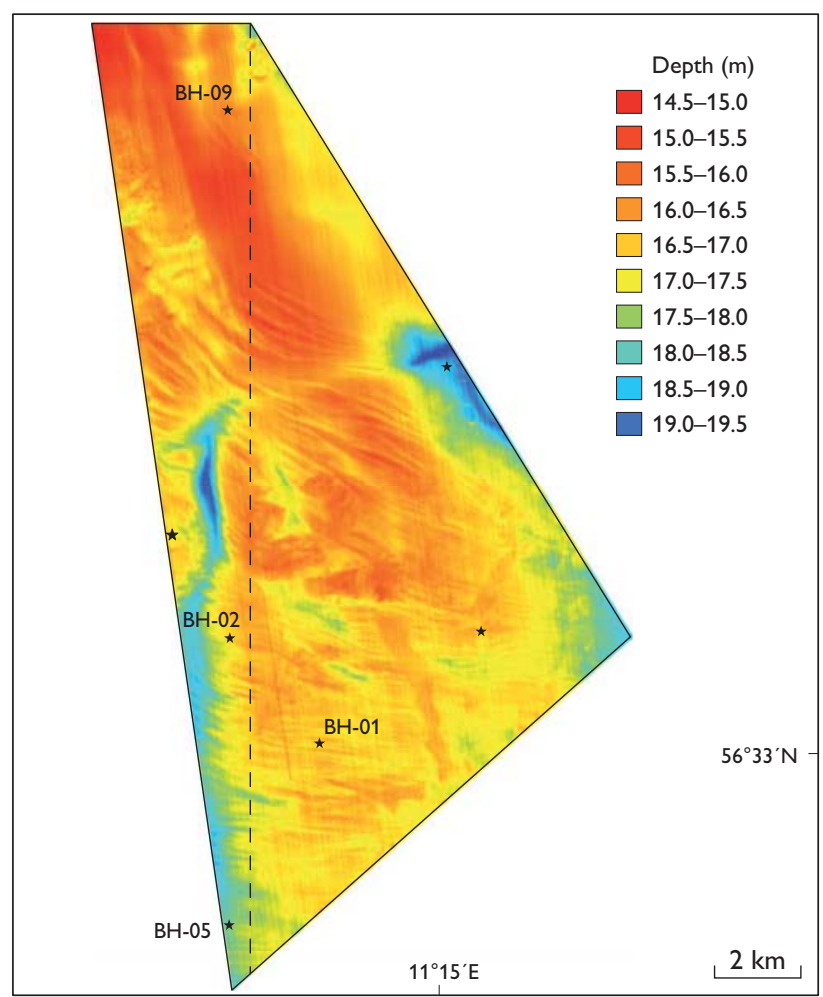

Fig. 2. Bathymetry of the survey area. The stars show sites with combined coring and cone penetration tests. The dashed line shows the position of the profile in Fig. 3. 


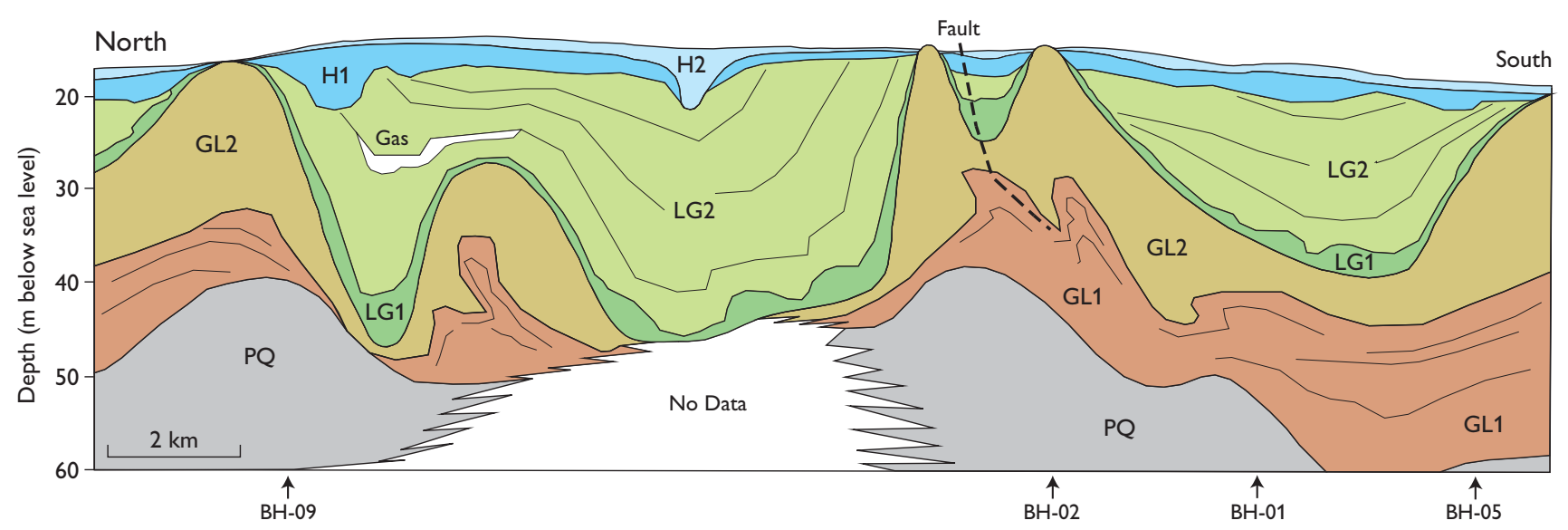

Fig. 3. Schematic model of the seismic units based on a N-S-trending section along UTM $634000 \mathrm{mE}$ (WGS84). The unit names refer to descriptions in the text. The boreholes (BH-01, BH-02, BH-05 and BH-09) are located at distances from $400 \mathrm{~m}$ to $1.5 \mathrm{~km}$ from the profile (Fig. 2).

dextral wrench faults that have repeatedly affected the Fennoscandian Border Zone (Lykke-Andersen et al. 1993). The latest major tectonic event was an inversion episode which started in the Late Cretaceous. After that inversion the Kattegat became an area of non-deposition and net-erosion until net-sedimentation was resumed in the Saalian. At that time the basin floor of the Kattegat was characterised by strongly undulating relief controlled by large- and small-scale structures in the pre-Quaternary basement.

The survey area can be divided into several subareas, based on bathymetry and seabed sediment types (Fig. 2). The northern part of the survey area is smooth, with sand and silt. The central and southern parts show ridges with a relief of more than $1 \mathrm{~m}$. It is suggested that the ridges were formed by waves at a time of lower than present sea level (Leth et al. 2009). The area with the highest density of gravel and boulders corresponds to the shallowest part of the central survey area. The boulders are generally located in arc-like, NWSE-striking, narrow structures found mainly in the southern and western parts of the survey area (Figs 1,2). Depths over $18 \mathrm{~m}$ characterised by sand and silt with pebbles occur near the western and eastern margins of the survey area.

\section{Pre-Quaternary strata - Unit PQ}

The pre-Quaternary surface is a regional erosional unconformity with high amplitude seismic reflection. The reflector has been mapped throughout the area down to the limit of the penetration of the sparker system at $c .60 \mathrm{~m}$ below sea level (b.s.l.; Figs 3, 4D). The pre-Quaternary surface lies deeper than $60 \mathrm{~m}$ b.s.l. in the eastern part of the area.

Two boreholes penetrated several metres of pre-Quaternary silty, fine sand. Analysis of palynomorphs in two samples yielded an Upper Cretaceous age (K. Dybkær and E. Sheldon, personal communication 2009).

\section{Glacial deposits - Unit GL}

The glacial deposits have been divided into two subunits, GL1 and GL2. The lower subunit GL1 is found in the central and southern parts of the survey area. It shows a characteristic medium- to low-amplitude, parallel, wavy and chaotic seismic pattern. The parallel or wavy pattern is interpreted as representing undisturbed sorted and layered sediments, whereas the wavy or chaotic pattern is interpreted as representing glacially dislocated sediments. A unit with a similar seismic character as GL1 has been found in various parts of the Kattegat, and has been referred to the Late Saalian, Eemian and Middle Weichselian (Vangkilde-Pedersen et al. 1993). Marine and glaciogene sediments of these ages have been recorded in sediment cores from other parts of the Kattegat region (Larsen et al. 2009).

The transition to seismic subunit GL2 is sharp in the southern part of the survey area, whereas it is more gradual in the central part. Internally GL2 shows a medium- to highamplitude, seismic facies pattern that is chaotic, mounded and channelled. Low-angle oblique reflectors cutting through the whole subunit are interpreted as large-scale, glaciotectonic deformation structures. Data from sediment samples show that the subunit mainly consists of sand with poorly and wellsorted layers of clay, silt and gravel. A high density of cobbles and boulders is seen where GL2 crops out on the sea floor, as confirmed by surface samples (Fig. 4A). A unit showing a similar seismic pattern and with similar deposits from the Lysegrund area (Fig. 1) has been interpreted as subglacial and glaciofluvial deposits. The GL2 subunit probably corresponds to the M3 unit at Lysegrund, which consists of icemargin sediments deposited during the retreat stage of the Main Advance (Novak 1996). The seismic pattern, facies association, unit morphology, sea-floor character and lithology all suggest that GL2 represents similar ice marginal deposits. 

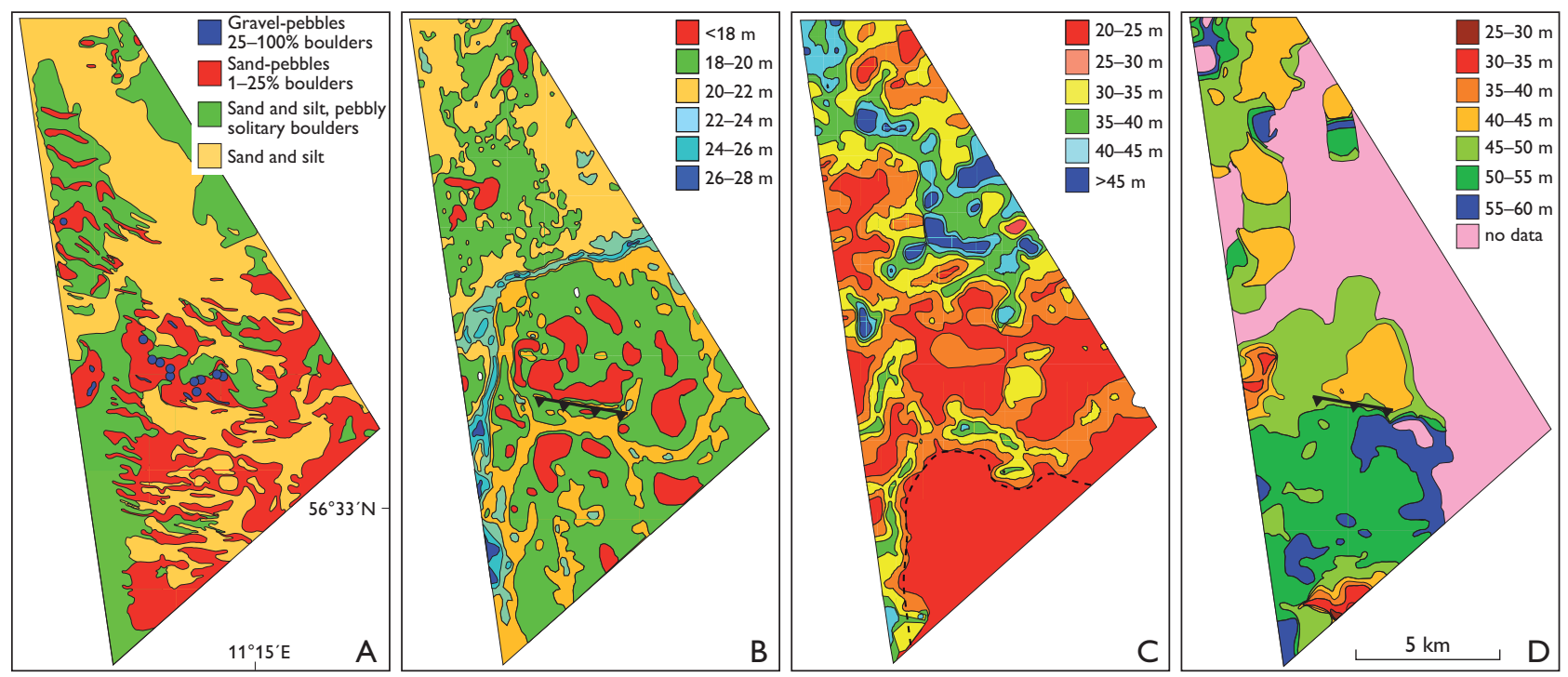

Fig. 4. Maps showing seabed sediments and three seismic stratigraphic levels. A: Seabed sediment types. B: Depth of base Holocene. Black line indicates fault. C: Depth to the top of the glacial deposits. The dashed line shows the disturbed-undisturbed GL1 interface (see text). D: Pre-Quaternary surface morphology. Black line indicates fault.

\section{Late glacial deposits - Unit LG}

The distribution of the late glacial seismic unit LG is governed by the morphology of the underlying glacial surface (Fig. 4C). Its maximum thickness is $45 \mathrm{~m}$. Towards the south the depressions in the glacial surface are characterised by shallow channels and small basins, and it is possible to correlate these depressions to a system of elongated fault-related basins in the pre-Quaternary surface SW of Anholt (Binzer \& Stockmarr 1994).

The seismic unit LG is subdivided into two subunits, LG1 and LG2, with a gradational boundary. LG1 shows an external apron or mound morphology with internal composite mounds as well as a hummocky, shingled, parallel reflection pattern. At its base, LG2 shows an onlap-downlap, draping style. Upwards it shows a gradually decreasing amplitude and a more pronounced semi-transparent, parallel seismic facies. In general, LG2 terminates upwards into an erosional unconformity. A seismic 'blacking out' area internally in LG2 indicates gas content in a discrete level associated with a pronounced reflector that probably represents a sealing clay layer.

Data from boreholes show that unit LG consists of a fining-upward sequence with sand and gravel at its base and layers of clay with sand and silt laminae towards its top. The characteristic seismic expressions of unit LG have also been recorded from other parts of southern Kattegat. For instance, Jensen et al. (2002) reported two stages in a Late Glacial unit located in elongated fault-related basins and suggested that the two stages are related to re-activation of normal fault activity in the elongated depressions in the period from 15 to 13.5 calendar ka BP.

\section{Holocene deposits - Unit H}

The transition from the late glacial to the Holocene unit $\mathrm{H}$ is seen as a shift to high-amplitude reflectors. Truncation of the rhythmic parallel facies of LG2 is succeeded by mounds, hummocky oblique and sub-parallel reflector patterns in the Holocene subunit $\mathrm{H} 1$. This subunit was previously referred to the Late Glacial (Leth et al. 2009), but after reassessment of the abrupt changes in the seismic signature and its distribution we conclude that the subunit is of early Holocene age. In the southern part of the survey area, 400-600 m wide channels orientated WSW-ENE and SSW-NNE are filled with Late Glacial and early Holocene ( $\mathrm{H} 1)$ deposits. The base level of $\mathrm{H} 1$ in these channels is around $22 \mathrm{~m}$ b.s.l. $\mathrm{H} 1$ is deposited above the truncated LG2 unit and its distribution is confined by the older LG basins. The same base level is found in wider areas in the north and is likewise unconformable to the underlying LG unit. A significantly deeper channel crosses the central survey area with internal seismic structures that indicate a unidirectional flow from west to east (H2; Fig 3). The base of this channel is generally at 26-28 m b.s.l. Locally the channel widens to $1000 \mathrm{~m}$.

Organic-rich sediments of Holocene age representing a lowstand at $35 \mathrm{~m}$ b.s.l. are well-known from the Kattegat area. After a fluvial event west of Lysegrund the water level stabilised at $34 \mathrm{~m}$ b.s.l. (Novak \& Björk 1998). Lagoonal deposits overlying truncated, rhythmic, Late Glacial clay-sand layers are found south-east of the survey area (Bennike et al. 2000; Novak \& Pedersen 2000). In a major area these sediments are mostly found between 35 and $24 \mathrm{~m}$ b.s.l. and have been dated to the early Holocene (Bennike et al. 2000). 


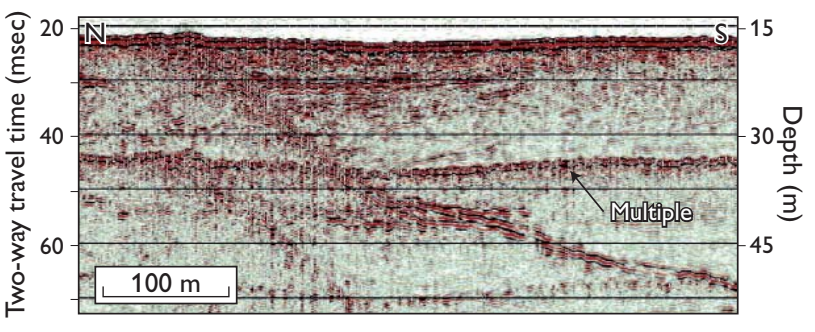

Fig. 5. Part of the N-S-orientated seismic profile AW039 showing a fault that dips to the south. A ridge is seen along the top of the fault. Note the subsidence of the seabed above the fault.

Lagoonal sediments at $18 \mathrm{~m}$ b.s.l., found $30 \mathrm{~km}$ east of the study area, were also dated to the early Holocene (Novak \& Pedersen 2000).

At most sites $\mathrm{H} 2$ only represents a veneer of fine- to coarse-grained sand with gravel, occasionally with silt and clay laminae as well as shell fragments of marine molluscs. However, in one of the samples marine shells and organic material are found at $9 \mathrm{~m}$ below the sea floor. It is suggested that the Early Holocene transgression reached a level high enough to submerge the survey area prior to 9.9 calendar ka BP. A channel in the central part of the survey area drained towards the east.

\section{Structural features}

In the central survey area, reflectors in the sparker profiles indicate listric normal faults dipping south-wards (Fig. 5). A $2.9 \mathrm{~km}$ long, E-W-striking sea-floor lineament (Fig. 4B, C) represents the top of the headwall scar, and the fault has a significant signature through the whole Quaternary package. The location and strike of the faults follow the structures in the pre-Quaternary basement (Binzer \& Stockmarr 1994), which indicates that they represent re-activations of old faults.

\section{Final remarks}

Based on geophysical data, boreholes and cone penetration tests we have documented that the geological architecture of the study area is very complex. The pre-Quaternary (Late
Cretaceous) basement is overlain by two glacial, two Late Glacial and two Holocene subunits. The widespread Late Glacial deposits that are up to $45 \mathrm{~m}$ thick are dominated by fine-grained sediments, in some areas with gas. The distribution of the Holocene deposits indicates the presence of channels that drained into the deeper part of the Kattegat during the early Holocene. The data described here are of great importance to the geotechnical evaluation prior to the planned foundation of windmills.

\section{Acknowledgements}

We thank Energinet.dk for permission to use the above data and to publish the geological results from the Anholt wind-farm project.

\section{References}

Bennike, O., Jensen, J.B., Konradi, P.B., Lemke, W. \& Heinemeier 2000: Early Holocene drowned lagoonal deposits from the Kattegat, southern Scandinavia. Boreas 29, 272-286.

Binzer, K. \& Stockmarr, J. 1994: Geological map of Denmark, 1:500 000. Pre-Quaternary surface topography of Denmark. Danmarks Geologiske Undersøgelse Kortserie 44, 10 pp., 2 maps.

Jensen, J.B., Petersen, K.S., Konradi, P., Kuijpers, A., Bennike, O., Lemke, W. \& Endler, R. 2002: Neotectonics, sea-level changes and biological evolution in the Fennoscandian Border Zone of the southern Kattegat Sea. Boreas 31, 133-150.

Larsen, N.K., Knudsen, K.L., Krohn, C.F., Kronborg, C., Murray, A.S. \& Nielsen, O.B. 2009: Late Quaternary ice sheet, lake and sea history of southwest Scandinavia - a synthesis. Boreas 38, 732-761.

Leth, J.O., Alhamdani, Z., Novak, B., Barzani, S.M. \& Hindrichsen, C. 2009: Anholt offshore wind farm. Marine geophysical investigations. Danmarks og Grønlands Geologiske Undersøgelse Rapport 2009/45, $411 \mathrm{pp}$.

Lykke-Andersen, H., Knudsen, K.L. \& Christiansen, C. 1993: The Quaternary of the Kattegat area, Scandinavia: a review. Boreas 22, 269-281.

Novak, B. 1996: En maringeologisk undersøgelse af kvartære lag på Lysegrund, sydlige Kattegat, Danmark. Geologisk Tidsskrift 2, 21-25.

Novak, B \& Björck, S. 1998: Marine seismic studies in southern Kattegat, with special emphasis on longitudinal bars and their possible relationship to the drainage of the Ancylus Lake. GFF 120, 297-306. Stockholm: Geological Society of Sweden.

Novak, B. \& Pedersen, G.K. 2000: Sedimentology, seismic facies and stratigraphy of a Holocene spit-platform complex interpreted from high-resolution shallow seismics, Lysegrund, southern Kattegat, Denmark. Marine Geology 162, 317-335.

Vangkilde-Pedersen, T., Lykke-Andersen, H. \& Lind, G. 1993: Dislocated Quaternary deposits in southeastern Kattegat - a glacial or gravitational phenomenon? Boreas 22, 329-336.

\footnotetext{
Authors' address

Geological Survey of Denmark and Greenland, ØsterVoldgade 10, DK-1350 Copenhagen K, Denmark. E-mail: jol@geus.dk
} 